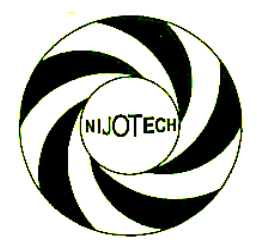

Nigerian Journal of Technology (NIJOTECH)

Vol. 36, No. 1, January 2017, pp. 87 - 95

Copyright(C) Faculty of Engineering, University of Nigeria, Nsukka,

Print ISSN: 0331-8443, Electronic ISSN: 2467-8821

www.nijotech.com

http://dx.doi.org/10.4314/njt.v36i1.12

\title{
EFFECTS OF NaOH MODIFICATION ON THE MECHANICAL PROPERTIES OF BAOBAB POD FIBER REINFORCED LDPE COMPOSITES
}

\author{
U. Shehu' ${ }^{1}$, M. T. Isa ${ }^{2,}$, B. O. Aderemi ${ }^{3}$ and T. K. Bello ${ }^{4}$ \\ 1 Petrochemical and Allied Dept., Nat. Research Institute for Chemical TeCh., Zaria, Kaduna State, NiGERIA \\ 2,3,4 Department of Chemical EngineERING, Ahmadu Bello University, Zaria, Kaduna State, NiGERIA \\ E-mail addresses: ${ }^{1}$ shehuusman33@yahoo.com,2mtisaz@yahoo.com,3elfemdor@yahoo.com, \\ 4tjbello27@yaoo.com
}

\begin{abstract}
In order to improve properties of natural fibers as reinforcement, different treatment methods have being adopted by researchers. However, the use of sodium hydroxide ( $\mathrm{NaOH}$ ) for the treatment of baobab pod fiber as reinforcement in low density polyethylene is sparsely reported. Therefore, this study, investigated the effect of $2 w t \%, 4 w t \% 6 w t \%, 8$ wt\% and 10 wt\% concentration of NaOH on baobab pod fibers as reinforcement for low density polyethylene (LDPE). Two roll mill machine and hydraulic press at a pressure of $10 \mathrm{kN}$ and temperature of $120^{\circ} \mathrm{C}$ aided the production of the composite. FT-IR was used to analyze the functional groups of the treated and un-treated fibers. The result showed the disappearance of the peak $1550 \mathrm{~cm}^{-1}$ corresponding to lignin after modification. Further, the composites were characterized for the following tensile strength (TS), modulus of elasticity (MOE), elongation at break, impact strength and water absorption. Preliminary studies on the effect of loading of the unmodified baobab fiber in the LDPE matrix showed desirable properties at $10 \mathrm{wt} \%$, where fiber content was in the range of $5 \mathrm{wt} \%$ to $30 \mathrm{wt} \%$ at interval of $5 \mathrm{wt} \%$. The composite produced from the $8 \mathrm{wt} \% \mathrm{NaOH}$ modified fiber had the highest tensile strength, MOE, elongation at break. At this modification level, the tensile strength, MOE and elongation at break were about $75.48 \%$, 92.18\% and $28 \%$ respectively higher than the composite produced from unmodified fiber. Composite produced with 10 wt\% NaOH modified fiber exhibited least water absorption of $1.80 \%$, which was $50 \%$ lower than unmodified. These showed that the modification of the fiber improved the composite properties. These properties compared favorably with some reported properties for natural fiber reinforced polymer composites.
\end{abstract}

Keywords: Alkaline modification, Tensile strength, Modulus of elasticity, Baobab fiber, FTIR.

\section{INTRODUCTION}

The use of natural fibers as reinforcement in polymer composites is gaining attention recently. This is because of environmental issues, high cost and unsustainable nature associated with conventional synthetic fibers [1 5]. Further, natural fibers have some advantages over their synthetic counterparts in term of physical, mechanical and biological properties; these include lower density, higher strength to weight ratio, higher specific properties, renewability and biodegradability. These make them useful in manufacture of bearings and linkages, building and automobile structures such as sliding panels [6].

Despite these desirable properties the application of natural fibers as reinforcements in the composite materials has some inherent challenges. This includes incompatibility with hydrophobic polymer matrix because of hydrophilic nature of the fibers. Additionally, fibers have tendency of forming aggregates. Consequently, researchers adopted different methods in the quest for improving the compatibility of natural fibers with hydrophobic matrix. One of such methods is the chemical treatment which activates hydroxyl chemical groups, to make the fiber compatible with the matrix [7]. Also, it alters the surface tension and the polarity of the fiber which aids the dispersion of the fibers in the matrix and improves adhesion of the fibers and the matrix [8].

Chemical methods such as mercerization (alkali treatment), silane treatment, benzoylation, peroxide treatment, permanganate treatment and use of some mild acids have been reported [9-13]. Silane treatment aids stability of composite materials, benzoylation caused reduction in the hydrophilicity of fiber hence interfacial adhesion is improved. Further, peroxide treatment helps to reduce fiber moisture content and 
also the thermal stability. On the other hand, alkali treatment is the cheapest and the most applied of all the methods; it removes lignin, hemicellulose, oils and waxes, with these components removed, cellulose is left, thereby increasing aspect ratio of the fiber, rough surface topology for proper adhesion of the fiber and the matrix [9].Using these treatment methods on fibers, different levels of properties modification have been achieved when used to reinforce matrix.

Optimum concentration of $10 \mathrm{wt} \% \mathrm{NaOH}$ treatment was reported for coir fiber reinforced polyester composite[14],for sisal fiber used as reinforcement in polyethylene $10 \mathrm{wt} \%$ was achieved as optimum [15], while $5 \mathrm{wt} \%$ was recorded for sisal reinforced polyester composite [12]. The use of other fibers such as banana [16], jute [17 and18], hemp [19] in composites production has been reported. However, literature on the use of baobab (Adansonia-digitata) in this area of application is scanty. Presently, their use is only limited to making of rope, string, cord for musical instruments, snares, fishing-nets, mats and waterproof hats[20]. These fibers are obtained either from the pod or bark of the tree. Strong fibers can also be obtained from the root bark. Baobab has one of the highest percentage elongation at break compared with some other fibers [21]. This premised the need to investigate the suitability of this fiber for producing composite materials. Therefore, the aim of this work is to study the effect NaoH modification on baobab pod fiber reinforced LDPE composite. Its suitability will add to the list of renewable and sustainable bio-fibers and can serve as substitute to other fibers. Due to the low compatibility between the hydrophilic fiber and hydrophobic matrix, treating baobab fiber chemically is a novel technique that will surely add to the archives of information to the body of knowledge in natural fiber-matrix composite processing and application.

\section{EXPERIMENTAL}

\subsection{Materials}

The Baobab pod fibers were sourced, extracted and treated with $\mathrm{NaOH}$ in National Research Institute for Chemical Technology (NARICT) Basawa, Zaria, Kaduna State, Nigeria while the low density polyethylene (Virgin) was purchased from Steve Moore Chemical Store Enterprise, Zaria Kaduna State Nigeria and used as purchased.

\subsection{Methods}

\subsubsection{Treatment of baobab fiber}

Sodium hydroxide solutions were prepared in $500 \mathrm{ml}$ beaker by diluting $8 \mathrm{~g}, 16 \mathrm{~g}, 24 \mathrm{~g}, 32 \mathrm{~g}$, and $40 \mathrm{~g}$ pellets of sodium hydroxide in $400 \mathrm{ml}(400 \mathrm{~g})$ of distilled water respectively to obtain concentration of $2,4,6,8$ and 10 wt\%[22].Baobab pod fibers of $1 \mathrm{~mm}$ size were soaked in the prepared $2 \mathrm{wt} \%$ of $\mathrm{NaOH}$ solution and heat at $40{ }^{\circ} \mathrm{C}$ for 1200 s on a regulated hot plate under a continuous stirring to ensure even modification. The fibers were rinsed severally with distilled water until a neutral $\mathrm{pH}$ prior to drying in an oven at $50^{\circ} \mathrm{C}$ for 1200 s. The same procedure was employed on baobab fibers at different concentration $(4,6,8$ and 10 wt \%) of $\mathrm{NaOH}$.

\subsubsection{Composite production}

Preliminary studies on the effect of loading of the unmodified baobab fiber in the LDPE matrix showed desirable properties at $10 \mathrm{wt} \%$, where fiber content was varied from $5 \mathrm{wt} \%$ to $30 \mathrm{wt} \%$ at interval of $5 \mathrm{wt} \%$. Consequently, the fiber weight was maintained at 10 wt $\%$ of the total composite weight for both the modified and unmodified baobab fibers. The fibers were mixed with LDPE in a two-roll mill machine model 5183, by Reliable Rubber Machinery Company, USA. The machine was preheated at the melting temperature of LDPE, $120^{\circ} \mathrm{C}$ in $1800 \mathrm{~s}$. LDPE constituting $90 \mathrm{wt} \%$ of the composite was poured into the preheated machine to melt for about 300s. Thereafter, the baobab fiber constituting $10 \mathrm{wt} \%$ was poured gradually into the melted LDPE until homogenous mixture was achieved. Finally, the compounded baobab/LDPE was removed from the mill in a form sheet.

Subsequently, a preheated (120 ${ }^{\circ} \mathrm{C}$ for 1800 s) hydraulic press model number 12000 , by Carver Incorporation, USA was used to produce the composites. Pre-sized compounded sheet placed in molds were placed on the preheated hydraulic press and compressed at pressure of $10 \mathrm{kN}$ for a period of 360s.Thereafter, the mold was allowed to cool and the composite sample removed from it. This procedure was used to produce composite samples from the modified baobab fiber of varying $\mathrm{NaOH}$ concentrations.

\subsection{Characterization}

\subsubsection{Fourier Transforms Infrared Spectroscopy (FTIR)}

The functional groups of the modified and unmodified baobab fibers were determined using Shimadzu machine (model: FTIR-84005) FT-IR spectrometer, Japan. The samples were dried in an oven at $60^{\circ} \mathrm{C}$. After which about $0.2 \mathrm{mg}$ of the specimens were placed on a Kbr plate and inserted into the infrared barrel. The infrared spectra of these samples were measured in a transmission wavelength number range between 4500 and $500 \mathrm{~cm}^{-1}$.

\subsubsection{Mechanical Properties and Water Absorption Tests}

Tensile testing of the composite specimens was carried out using an Instron Machine Model 3369, System 
Number 3369K1781, Capacity 50kN, USA. ASTM D638 [23] was adopted and three samples were tested and the mean recorded as representative value. The tensile test; from the test, the tensile strength, MOE and elongation at break were obtained. The impact test was conducted using impact testing machine serial number 412-0715269C, by Norwood Instrument Limited, Great Britain. The test was conducted according to ASTM D256 [23].ASTM D570-98[24] was used to carry out water absorption capacity of the samples and Equation (1)used to calculate the percentage of water absorbed.

\%water absorbed $=\frac{W_{f}-W_{i}}{W_{i}} \times 100$

In (1), $\mathrm{W}_{\mathrm{i}}(\mathrm{g})$ is the initial weight of dry sample; $\mathrm{W}_{\mathrm{f}}(\mathrm{g})$ is final weight of the sample after soaking.

Three samples were used for each test and the mean value of the water absorption and their corresponding standard error was calculated.

\section{RESULTS AND DISCUSSION}

\subsection{FTIR Spectra of Modified and Unmodified Baobab Fiber}

The FT-IR spectra of the unmodified and sodium hydroxide modified baobab fibers are shown in Figure 1 while the peak positions and their corresponding assignments are given in Table 1.Changes were observed in the FT-IR spectra of the modified baobab fibers when compared to the unmodified fibers. There was change in the intensity of the characteristic peak $\left(3850 \mathrm{~cm}^{-1}\right)$ of C$\mathrm{H}$ group stretching corresponding to hemicelluloses in the unmodified fiber to $2533 \mathrm{~cm}^{-1}$ after modifying. The peak $1683 \mathrm{~cm}^{-1}$ of bonded $\mathrm{OH}$ groups in the unmodified fiber changed to $1669 \mathrm{~cm}^{-1}$ in the modified fiber.

The band at $1669 \mathrm{~cm}^{-1}$ attributed to the stretching vibrations of $\mathrm{OH}$ groups disappeared after the modification process at $10 \mathrm{wt} \%$. Its absence in the 10 $\mathrm{wt} \%$ modified fiber indicated that lignin had been removed through the modification[25, 26 and 27].The use of alkaline treatment reduces or removes the amount of lignin, wax and oils covering the outer cell wall of the fiber, depolymerizing cellulose hence exposing the short length crystallites. The disturbance of the hydrogen bond in the network structures increases the surface roughness of the fiber [9]. It is reported that one way of improving fiber-matrix adhesion at the interface is through good mechanical keying [28]. Therefore, the changes resulting from modifications as shown by the FT-IR will lead to increase in surface roughness, hence good chance of mechanical keying and probably better mechanical properties of treated fiber reinforced polymer composites.

Table 1: Infrared transmittance peaks $\left(\mathrm{cm}^{-1}\right)$ and possible assignments of chemical groups in unmodified and NaOH modified baobab fiber

\begin{tabular}{lll}
\hline Wave number $\left(\mathrm{cm}^{-1}\right)$ & NaOH modified & \\
\hline Unmodified Fiber Peak & Fiber Peak & Peak assignment \\
3850 & - & C - H stretching in cellulose \\
2495 & 2425 & C - H stretching ${\mathrm{C} \mathrm{H} \text { and } \mathrm{CH}_{2} \text { in }}^{\text {hemicelluloses }}$ \\
1683 & 1666 & Stretching vibrations of OH groups \\
1528 & 1526 & $\mathrm{CH}_{2}$ symmetric bending \\
1193 & 1205 & $\mathrm{C}-\mathrm{H}_{2}$ bending in cellulose and \\
\end{tabular}

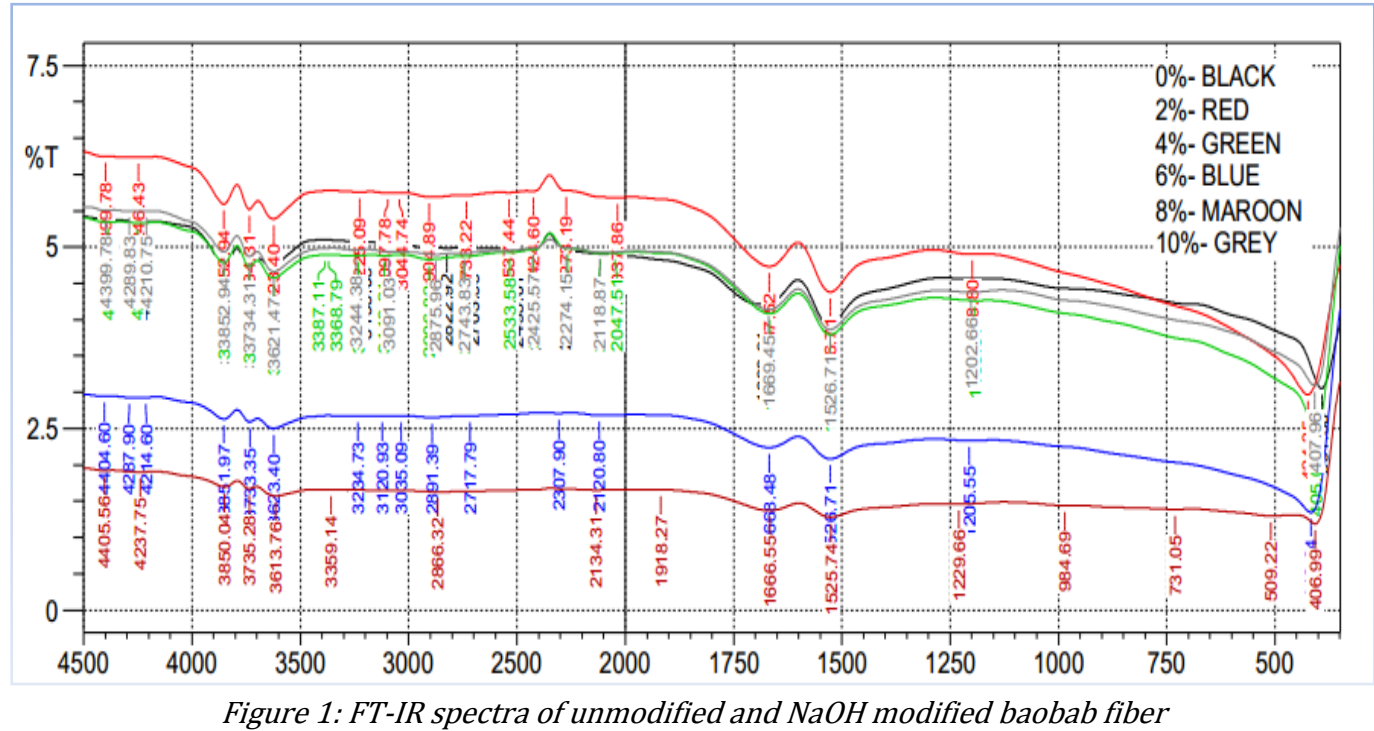




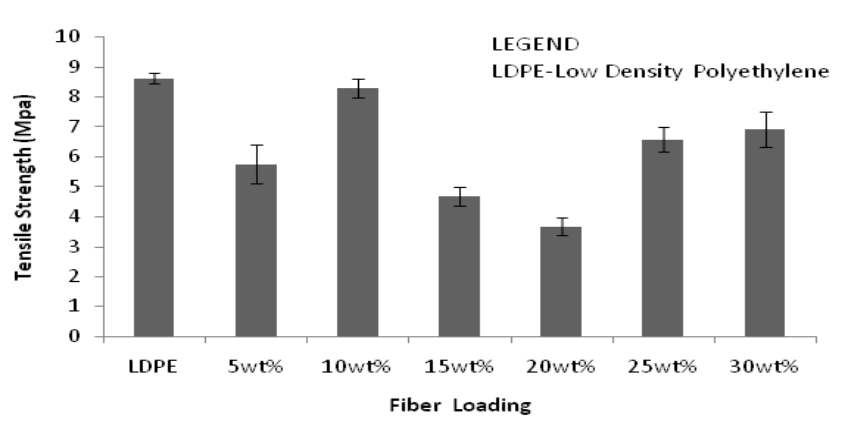

Figure 2: Effect of fiber loading on the tensile strength of

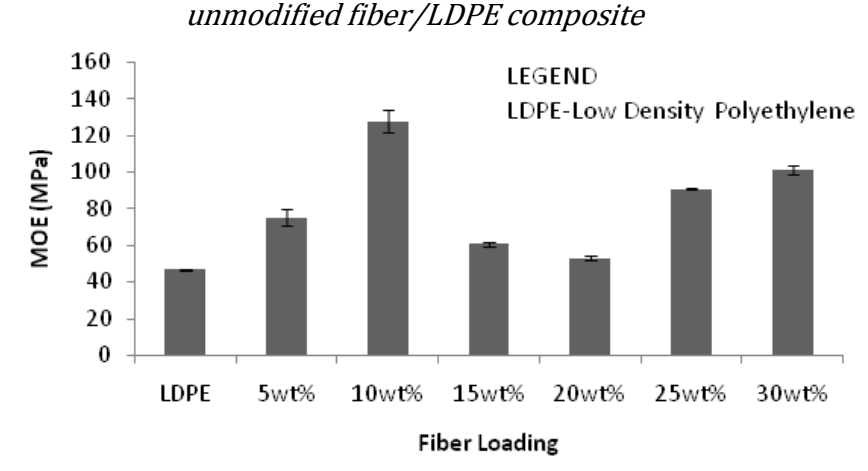

Figure 3: Effect of Fiber loading on MOE of unmodified fiber/LDPE composite

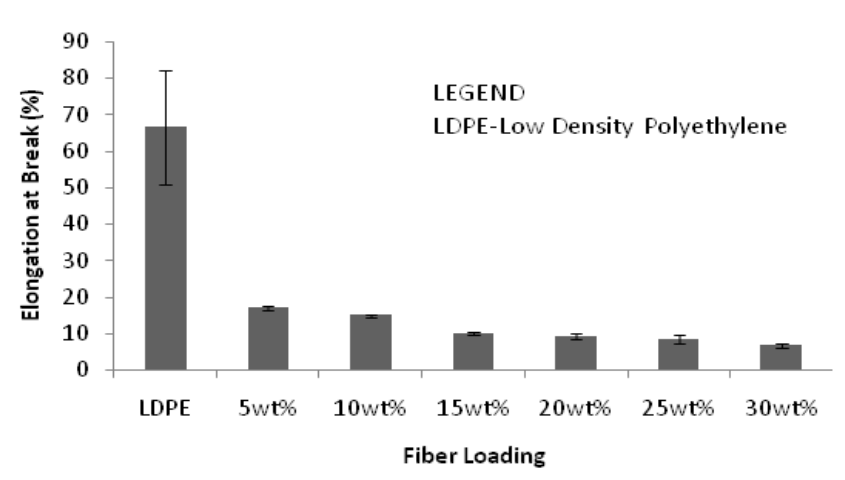

Figure 4: Effect of fiber loading on elongation at break of unmodified fiber/LDPE composite

\subsection{Mechanical Properties of Unmodified Fiber/LDPE Composites}

\subsubsection{Tensile strength of unmodified Fiber/LDPE composites}

Figure 2 presents effect of fiber loading on the properties of the composites produced from the unmodified baobab pod fiber. The unreinforced low density polyethylene (LDPE) had the higher tensile strength than the LDPE reinforced with unmodified baobab fiber. The decrease in the tensile strength between the reinforced and unreinforced LDPE might be due to the weak fiber and matrix interface resulting from the presence of impurities, lignin and waxes on the fiber. However, 10 wt $\%$ baobab fiber reinforced LDPE had the highest tensile strength among the reinforced LDPE, which decreased with increasing the fiber loading. The decrease could be as a result of fiber-fiber interaction at higher fiber content whereby load was not effectively transferred through the matrix to the fiber [17]. At higher fiber content, poor interfacial bonding between the fiber and the matrix may occur due to excess fiber, hence, reduction in properties. The $8.28 \mathrm{MPa}$ obtained for $10 \mathrm{wt} \%$ was lower than the optimal value of $10.4 \mathrm{MPa}$ for Dum palm fiber-polyester composites [29] and 9.5 MPa for luffa-polyester composite [30].

\subsubsection{MOE of Unmodified Fiber/LDPE composites}

The effect of fiber loading on the Modulus of elasticity (MOE) produced composites is presented in Figure 3. As indicated in the figure, $10 \mathrm{wt} \%$ fiber loading exhibited the highest modulus of elasticity of $127.8 \mathrm{MPa}$. This suggests that the $10 \mathrm{wt} \%$ fiber loading composite exhibit highest degree of stiffness within the fiber loadings investigated. However, the drop in MOE after $10 \mathrm{wt} \%$ loading might be attributed to poor dispersion of fiber in the matrix at higher loading in addition to poor fibermatrix interaction [17].

\subsubsection{Elongation at Break of Unmodified Fiber/LDPE Composites}

The result of the effect of fiber loading on the elongation at break of composites as presented in Figure 4 indicated that the elongation of the unreinforced LDPE was clearly higher than any of the reinforced baobab fiber composites. The elongation at break decreases with increasing fiber loading, with the elongation at break of 5 wt\% baobab fiber reinforced composite slightly higher than that of $10 \mathrm{wt} \%$. Increase in fiber content could result to this as the fiber is stiffer than the matrix hence polymer-polymer chain is broken by the fiber, hence reduction in elongation. The highest elongation at break of $17.13 \%$, obtained in this work was higher than $1.98 \%$ and $0.94 \%$ elongations for Dum palm and luffa fiber reinforced polyester composites respectively [29, 30].

\subsubsection{Impact strength of unmodified Fiber/LDPE composites}

Figure 5 presents the effect of fiber loading on impact strength of unmodified fiber reinforced LDPE composite. Lower energy was required to break the composites material as compared to the virgin LDPE composite. The impact strength of the composites decreased with increasing fiber content, from $4.20 \mathrm{~J} / \mathrm{mm}^{2}$ to $1.57 \mathrm{~J} / \mathrm{mm}^{2}$. The trend observed could be as a result of increase in the stiffness of the composite as the fiber content was increased [31]. The highest impact was obtained at 5 wt\% fiber loading, however the overlap in the error bar between $5 \mathrm{wt} \%$ and $10 \mathrm{wt} \%$ fiber loading, indicated that there was no significant difference in the impact strength of the two composites. 


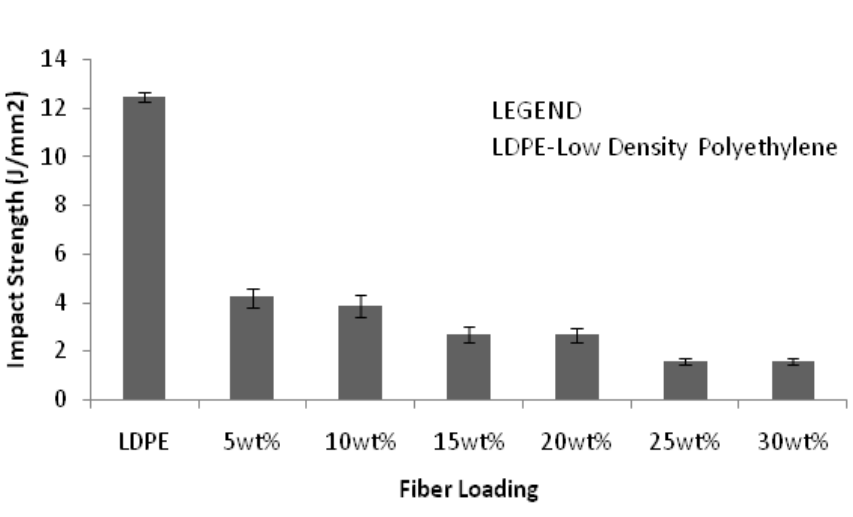

Figure 5: Effect of fiber loading on impact strength of unmodified fiber /LDPE composite

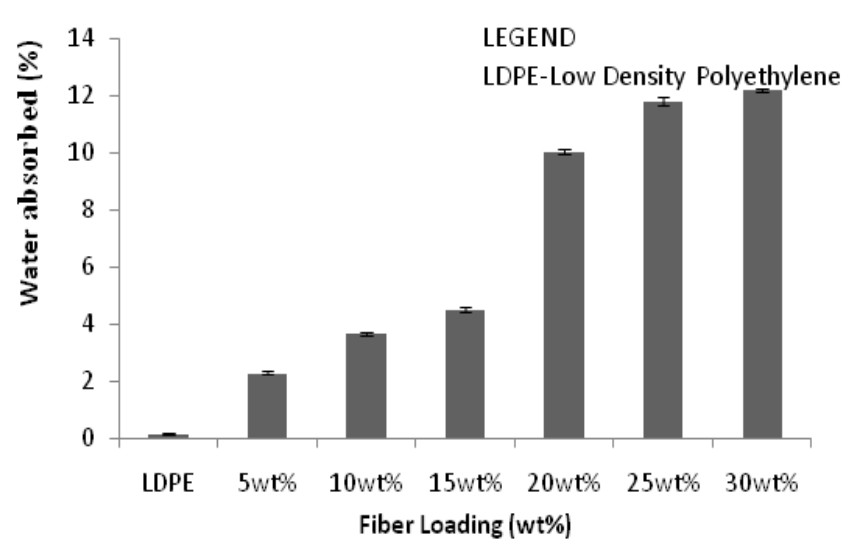

Figure 6: Effect of fiber loading on water absorption of unmodified fiber/LDPE composite

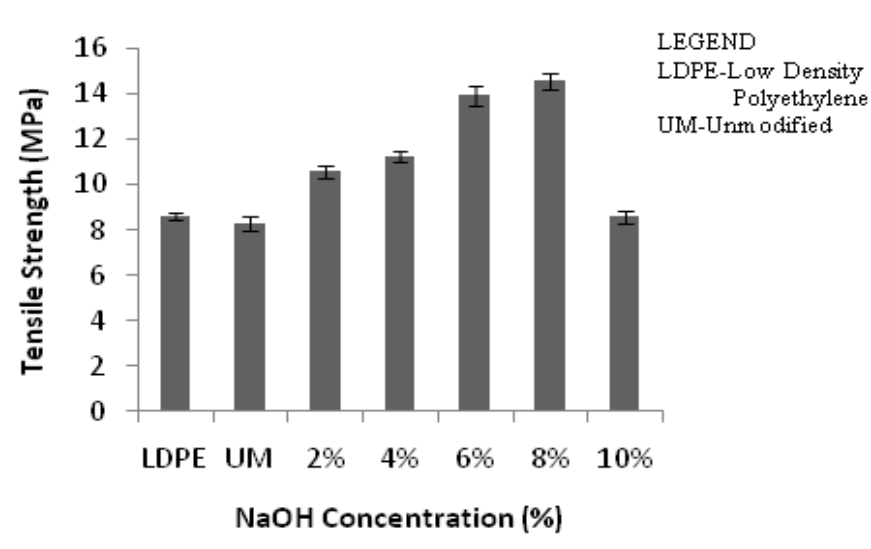

Figure 7: Effect of fiber modification on the tensile strength of the composite

The highest impact strength of $4.20 \mathrm{~J} / \mathrm{mm}^{2}$ obtained in this work was lower than the optimal value of 4.50 $\mathrm{J} / \mathrm{mm}^{2}$ at $5 \mathrm{wt} \%$ fiber loading for PALF-polyethylene composite [32], $4.80 \mathrm{~J} / \mathrm{mm}^{2}$ at $5 \mathrm{wt} \%$ fibre content for palm-epoxy composite [33] and $5.6 \mathrm{~J} / \mathrm{mm}^{2}$ at $5 \mathrm{wt} \%$ fiber loading in jute-coir fiber reinforced hybrid polypropylene composite [17], but higher than impact strength value of $0.008 \mathrm{~J} / \mathrm{mm}^{2}$ at 5 wt $\% \mathrm{NaOH}$ concentration treated luffa fiber reinforced epoxy matrix composite [34]. These could be as a result of the difference in the nature of the fibers or the matrix used.

\subsubsection{Water Absorption of Unmodified Fiber/LDPE Composites}

It was observed that the unreinforced virgin low density polyethylene absorbed the minimal percentage of moisture due to it hydrophobic nature and on reinforcing with the baobab fiber, the capacity to absorb moisture increases as a result of the introduction of the hydrophilic baobab fiber. The water absorption of the composites increased with increasing fiber content. Similar trend has been reported [35]. Natural fibers are known to hydroxyl group which easily absorbed moisture because of the formation of hydrogen bonding [36]. Higher fiber content could also result to higher voids entrapped in the composites, hence, higher water accumulation at the interface between fiber and matrix [37].

\subsection{Mechanical Properties of Modified Fiber/LDPE Composites}

\subsubsection{Tensile Strength}

Figure 7, shows the effect of fiber modification on the tensile strength of baobab fiber reinforced low density polyethylene composite. It was observed the tensile strength of the composites produced with the fibers modified $\mathrm{NaOH}$ solution concentrations of $2 \mathrm{wt} \%, 4 \mathrm{wt} \%$, $6 \mathrm{wt} \%$ and $8 \mathrm{wt} \%$ were higher than the unmodified after which there was drop in tensile strength. This can be considered as positive effect of modification thereafter a negative effect. The composite resulting from $8 \mathrm{wt} \%$ concentration of $\mathrm{NaOH}$ solution modified baobab fiber exhibited the highest tensile strength of $15 \mathrm{MPa}$, which was75.48\% higher than the unmodified baobab fiber composite.

The improved tensile strength observed at $2 \mathrm{wt} \%, 4$ wt $\%, 6$ wt $\%$ and 8 wt $\%$ of $\mathrm{NaOH}$ solutions may be attributed to the improved fiber-LDPE interface, resulting from better adhesion after the fiber was chemically modified, while the observed decrease in tensile strength could be attributed to fiber damage at higher concentrations of $\mathrm{NaOH}$ which could decrease the strength of the composite [14].

The highest tensile strength (TS) value of $15 \mathrm{MPa}$ obtained at $8 \mathrm{wt} \% \mathrm{NaOH}$ solution modified fiber was higher than $12 \mathrm{MPa}$ reported for coir fiber reinforced polyester composite in which $10 \mathrm{wt} \%$ fiber and $10 \mathrm{wt} \%$ alkali treatment were used [14]. The TS was also higher than the $7.65 \mathrm{MPa}$ reported for $20 \mathrm{wt} \%$ crushed luffa fiber reinforced recycled low density polyethylene (rLDPE) [22]. The TS obtained in this work was generally lower than reported values for synthetic fiber such as glass that is commonly use. The TS in this work was higher than $1.601 \mathrm{MPa}$ for woven mat reinforced polyester, but much lower than 395.8 MPa for woven 
mat reinforced with siloxane modified polyester, 64.4 MPa virgin glass fiber reinforced polyester [38].

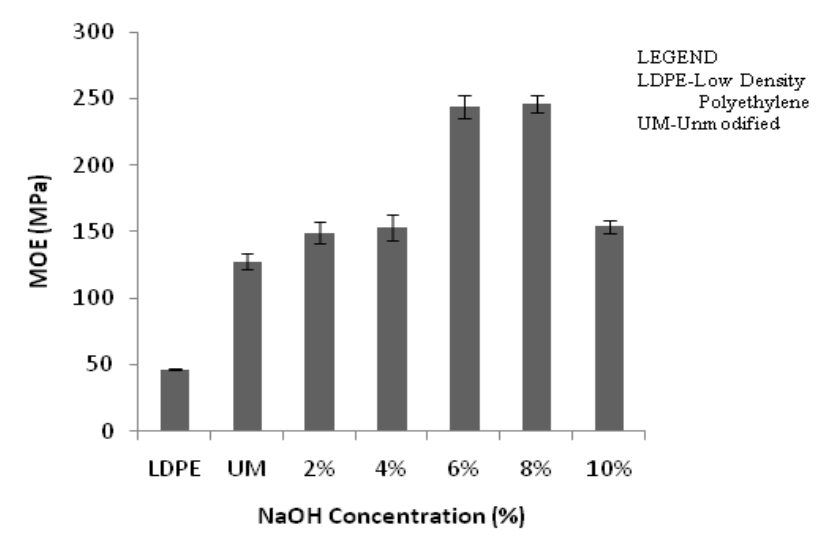

Figure 8: Effect of baobab fiber modification on MOE of the composite

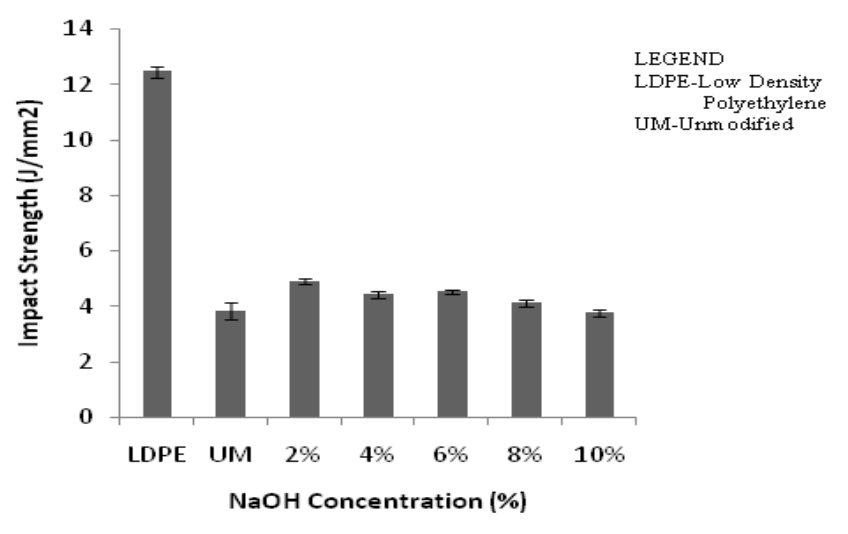

Figure 9: Effect of baobab fiber modification on the impact strength of the composite

\subsubsection{Modulus of Elasticity (MOE)}

Effect of fiber modification on the MOE of baobab fiber reinforced LDPE is presented in Figure 8.The $8 \mathrm{wt} \%$ $\mathrm{NaOH}$ modified baobab fiber composite exhibited the highest modulus of elasticity of $246 \mathrm{MPa}$. This suggests that the $8 \mathrm{wt} \%$ modified baobab fiber composite exhibit highest degree of stiffness compared to the other composites, i.e. composites reinforced with unmodified baobab fiber and those produced with fibers treated with $2 \mathrm{wt} \%, 4 \mathrm{wt} \%, 6 \mathrm{wt} \%$ and $10 \mathrm{wt} \% \mathrm{NaOH}$ solutions. The enhancement in the MOE after the $\mathrm{NaOH}$ modification could be attributed to the fact that the modification resulted to increase in the roughness of the fiber, hence increase contact area with the matrix. Crystallinity index of the fibers may also have been improved because of the removal of cementing materials such as lignin. It was reported that removal of cementing materials led to better packing of the cellulose chains, therefore improved mechanical properties of fibers [29].The decreased value of MOE observed after the 8 wt $\%$ concentration of $\mathrm{NaOH}$ may be attributed to the damage on the fiber surface as a result of high concentration of chemical used for the modification thereby making fibers loss their characteristics [9].
Optimal $\mathrm{NaOH}$ treatment of $8 \mathrm{wt} \%$ for luffa- rLDPE composite has been reported [22] and $10 \mathrm{wt} \%$ was reported for short sisal polyethylene composites [15]. The highest MOE obtained in this work was higher than reported MOE of Dum-palm fiber polyester composite of 64.15 MPa [29], 18.98 MPa established for crushed luffa fiber reinforced rLDPE [22]. However, it was much lower than $500 \mathrm{MPa}$ reported for epoxy reinforced luffa fiber [32]. Fiber type, matrix type and fiber loading may be responsible for the differences noted [39]. The MOE was lower than glass fiber reinforced polyester in all cases. It was lower than 80.5 MPa for woven mat reinforced polyester, but much lower than $18000 \mathrm{MPa}$ for woven mat reinforced with siloxane modified polyester, 7200 MPa virgin glass fiber reinforced polyester [38]. This is expected as synthetic fibers are generally stiffer than natural fibers.

\subsubsection{Impact strength}

The effect of fiber modification on the impact strength of the baobab reinforced LDPE is presented in Figure 9.

A positive modification effect was observed with the modified fiber composites compare to the unmodified fiber composite. There was about $23 \%$ increase in the impact strength of the composite made with baobab fiber modified with $2 \mathrm{wt} \% \mathrm{NaOH}$ solution compared to the unmodified baobab fiber composite. The increase in the impact strength may be attributed to the increase in the fiber surface roughness, resulting in better mechanical interlocking and the increased amount of cellulose exposed on the fiber surface [40].

There was decrease in impact strength after the $2 \mathrm{wt} \%$ $\mathrm{NaOH}$ solution modification. It was reported that if the $\mathrm{NaOH}$ concentration is higher than the optimum condition, the excess delignification of the fibers can take place resulting to weakening or damaging of fibers and consequent decrease in impact strength of the composite may occur [9].

The highest impact strength of $4.91 \mathrm{~J} / \mathrm{mm}^{2}$ obtained from 2 wt\% $\mathrm{NaOH}$ modified baobab fiber was higher when compared with the impact strength value of $0.008 \mathrm{~J} / \mathrm{mm}^{2}$ at $5 \mathrm{wt} \% \mathrm{NaOH}$ concentration treated luffa fibre reinforced epoxy matrix composite [34]. The value was also higher than $4.50 \mathrm{~J} / \mathrm{mm}^{2}$ at $5 \mathrm{wt} \%$ fiber loading for PALF-polyethylene composite [29], $4.80 \mathrm{~J} / \mathrm{mm}^{2}$ at $5 \mathrm{wt} \%$ fiber content for palm-epoxy composite [33] but lower than $5.6 \mathrm{~J} / \mathrm{mm}^{2}$ at $5 \mathrm{wt} \%$ fiber loading in jute-coir fibre reinforced hybrid polypropylene composite [17]. The variation could be as a result of the difference in the properties of the fibers or the matrix used. The impact strength obtained in this work was generally higher than the reported values for glass fiber reinforced polymers. It was higher than $0.017 .6 \mathrm{~J} / \mathrm{mm}^{2}$ reported for chopped 
strand glass fiber reinforced epoxy resin and 0.1535 $\mathrm{J} / \mathrm{mm}^{2}$ for glass fiber reinforced polyester modified with sodium montmorillonite [38]. Glass fibers are known to be stiffer than the natural fibers, hence the reason for the observed superior impact strength of the composites from natural fiber.

\subsubsection{Elongation at Break}

Figure 10 presents the effect of fiber modification on the elongation at break of the composite. The composite produced from fiber modified with $8 \mathrm{wt} \%$ concentration of $\mathrm{NaOH}$ solution exhibited the highest percentage elongation at break of $20.75 \%$. This was about $28 \%$ higher than the unmodified baobab composite. The enhanced percentage elongation on modification could be as a result of the removal of hemicelluloses, lignin, wax and pectin from the fiber. The removal of the impurities may have exposed more areas on the fiber surface for better contact with the matrix [41].

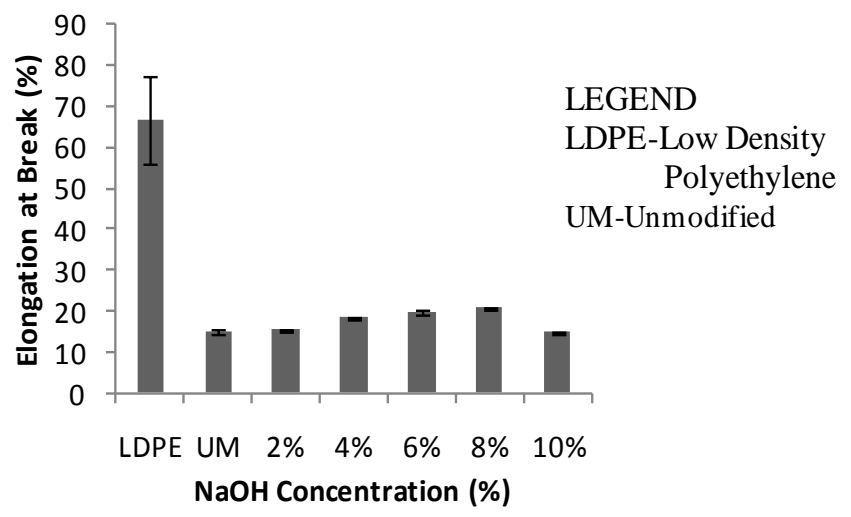

Figure 10: Effect of baobab fibre modification on the elongation at break of the composite

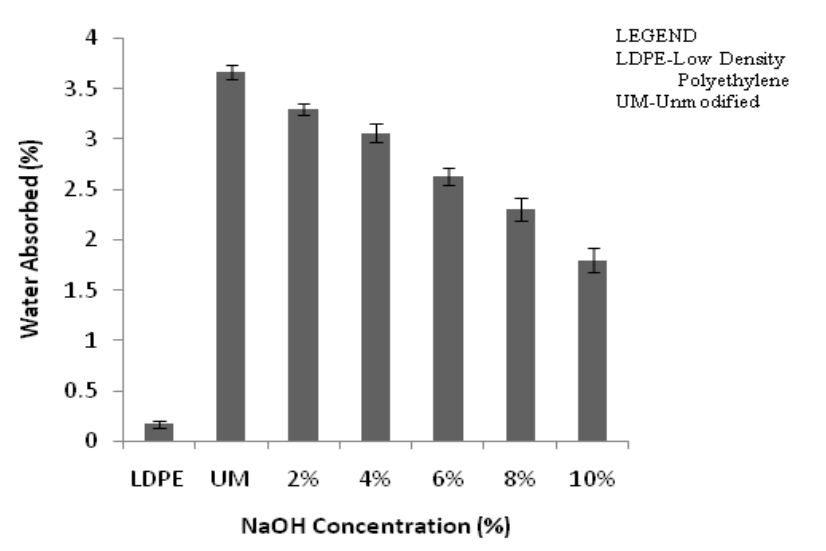

Figure 11: Effect of baobab fibre modification on water absorption of the composite

However, at very high $\mathrm{NaOH}$ modification concentration of $10 \mathrm{wt} \%$, deterioration in the fiber properties could have occurred. This may be due to excess delignification of the fibers, which results in weakening or damaging of the fibers [9]. An optimal of $10 \mathrm{wt} \% \mathrm{NaOH}$ treatment was reported for randomly arranged sisal-polyethylene composites with $27 \%$ elongation at break [15], this was higher than the highest elongation at break obtained in this work. The elongation at break in this work was generally higher than values reported for glass fiber composites. It was higher than $3.9 \%$ for woven mat reinforced with siloxane modified polyester, $1.8 \%$ virgin glass fiber reinforced polyester, but lower than $20 \%$ for woven mat reinforced polyester [38].

\subsubsection{Water Absorption}

Figure 11 presents the effect of fiber modification on water absorption of the composite. As shown in the figure, water absorption capacity of the composites dropped from $3.7 \%$ to $3.3 \%$, when the fibers were modified with $2 \mathrm{wt} \%$ concentration of $\mathrm{NaOH}$ solution. With further increase in $\mathrm{NaOH}$ concentrations, there was further decrease in water absorption of the composites as compared to the unmodified. The reduction in the water absorption could result from the surface modification of the fiber [8]. It was reported that on treatment of biofibers with alkali, sensitive hydroxyl groups are weakening hence easily react with water molecules and removed from the structure of the fiber [42].The fiber's moisture resistance property was improved as a result of the reduced hydrophilic hydroxyl groups. The least water absorption of $1.8 \%$ recorded at $10 \mathrm{wt} \% \mathrm{NaOH}$ modification in this study was lower than the reported $2.8 \%$ at optimal treatment concentration of 10 wt $\% \mathrm{NaOH}$ [27]. This was higher than $0.5531 \%$ reported for $5 \mathrm{wt} \% \mathrm{NaOH}$ luffa fiber reinforced epoxy [35].The water absorption of glass fiber reinforced polyester composite was reported as $0.3962 \%$ [39]. The one obtained in this work was higher.

\section{CONCLUSION}

The present study established the potential of baobab pod fiber as bio-fiber as reinforcement in LDPE to produce composites. The effects that chemical modification by $\mathrm{NaOH}$ has on the bio-fiber, and hence the composites were presented. The following conclusions are therefore made:

The FT-IR analysis of unmodified and modified baobab fiber showed that, there was reduction intensity of the band representing hemicelluloses and disappearance of the lignin band in the $\mathrm{NaOH}$ modified fiber. This resulted to improved properties of the composites made from the modified fiber.

Most of the studied composites properties were highest at $10 \mathrm{wt} \%$ unmodified baobab pod fiber loading. Baobab fiber composites produced from $8 \mathrm{wt} \% \mathrm{NaOH}$ solutions modified fibers exhibited75.48\%, 92.18\% and 28\% tensile strength, modulus of elasticity (MOE) and elongation at break respectively higher than unmodified 
baobab fiber composite. Composite produced from 2 wt $\% \mathrm{NaOH}$ modified fiber showed highest impact strength of $4.91 \mathrm{~J} / \mathrm{mm}^{2}$. This was $23 \%$ higher than the composite from the unmodified fiber. Composites produced from modified fiber at $10 \mathrm{w} \% \mathrm{NaOH}$ solutions had the least water absorption and this was $50 \%$ lower than the unmodified. This was an indication that the modification had effect on the properties of the composites and the results compared favorably with other reported works.

Consequently, the forgoing attests to the promising potential of fiber as reinforcement in composite materials production. This succinctly shows the economic importance of the study.

\section{REFERENCES}

[1] Jawaid, M. ,Abdulkhalil, H. P. S., Cellulosic/Synthetic Fibre Reinforced Polymer Hybrid Composites: A Review, Carbohydrate Polymers, 86(1), 1-18.,2011.

[2] Puglia,D.,Biagiotti, J., Kenny, J. M., A Review on Natural Fibre-Based Composites Part II,Journal of Natural Fibres,1(3), 23-65. 2005.

[3] Abdulkhalil, H. P. S. ,Bhat,I.U.H., Jawaid, M., Zaidon , A, Hermawan, D. Hadi, Y.S., Bamboo Fibre Reinforced Biocomposites: A Review, Materials and Design, 42, 353368. 2012

[4] Li, Y., Mai, Y. W., Ye, L., Sisal Fibre and its Composites: A Review of Recent Developments, Composites Science and Technology, 60 (11), 2037-2055. 2000.

[5] Mishra, S., Mohanty, A. K., DrzalL, T., Mishra M., Hinrichsen G., A Review on Pineapple Leaf Fibers, Sisal Fibers and their Biocomposites, Macromolecular Materials Engineering, 289- 955. 2004.

[6] Wambua, P., Ivens, J Verpoest, I. Natural Fibers: Can They replace Glass in Fiber Reinforced Plastics, Composite Science and Technology,63(9), 1259-1264. 2003.

[7] Nguong, C. W., Lee, S. N. B., Sujan, D., A Review - On Natural Fibre Reinforced Polymer Composites, Journal of World Academia of Science, Engineering and Technology, 73. 2013.

[8] Kumar, R., Obrai, S., Sharma, A., Chemical Modifications of Natural Fibre for Composite Material, Der Chemica Sinica, 2 (4), 219-228. 2011.

[9] Li, X., Tabil, L.G., Panigrahi, S., Chemical Treatment of Natural Fibre for use in Natural Fibre-Reinforced Composites: A Review, Journal of Polymer and Environments, 15(1), 25-33. 2007.

[10] Liu, L., Yu, J., Cheng, L., Qu, W., Mechanical Properties of Poly (Butylene Succinate) (PBS)Bio-Composites Reinforced with Surface Modified Jute Fibre, Composites, Part A, 40 (5), 669-674. 2009.

[11] Patel, V. A., Parsania, P.H., Performance Evaluation of Alkali and Acrylic Acid Treated-Untreated Jute Composites of Mixed Epoxy-Phenolic Resins, Journal of Reinforce Plastic Composites, 29(5):725-730. 2009.
[12] Mishra, S., Mohanty, A. K., Drzal, L. T., Misra, M., Parija, S., Nayak, S. K.,, Studies on Mechanical Performance of Biofiber/Glass Reinforced Polyester Hybrid Composites, Composites Science and Technology, 63(10), 1377-1385. 2003.

[13] Paul, S. A., Oommen, C., Joseph, K., Mathew, G., Thomas, S., The Role of Interface Modification on Thermal Degradation and Crystallization Behaviour of Composites from Commingled Polypropylene Fibre and Banana Fibre,Polymer Composites, 31(6),1113-23. 2010.

[14] Corrales, F., Vilaseca, F., Llop, M., Gironès, J., Méndez J. A., Mutje, P., Chemical Modification of Jute Fibres for the Production of Green-Composites, Journal of Hazardous Materials, 144 (3), 730-5. 2007.

[15] Joseph, P. V, Kuruvilla, J., Thomas, S., Effect of Processing Variables on the Mechanical Properties of Sisal Fibre Reinforced Polypropylene Composite, Composite Science and Technology, 59(11), 1625 - 1640.1999.

[16] Albinante, S. R., Pacheco, E.B.A.V., Visconte, L. L. Y. Platenik, G., Batista ,L.N., Modification of Brazilian Natural Fibers from Banana's Tree to Apply as Fillers into Polymers Composites, Chemical Engineering Transactions, 37, , 715-720. 2014.

[17] Siddika, S., Mansura, F., Hasan, M., Hassan, A., Effect of Reinforcement and Chemical Treatment on the Properties of Jute-Coir Fibre Reinforced Hybrid Polypropylene Composites, Fibres and Polymers, 15 (5), 1023-1028. 2014.

[18] Mishra, H. K., Dash, B. N., Tripathy, S. S., Padhi, B.N., A Study on Mechanical Performance of Jute-Epoxy Composites, Polymer-Plastic Technology Engineering, 39 (1), 187-198. 2000.

[19] Singh, S., Deepak, D., Aggarwal, L., Gupta, V. K., Tensile and Flexural Behavior of Hemp Fiber Reinforced VirginRecycled HDPE Matrix Composites, Procedia Materials Science, 6, ,1696-1702. 2014.

[20] Sidibe, M., Williams, J. T., Baobab, Adansonia digitata, International Centre for Underutilized Crops, Southampton, UK, 59. 2002.

[21] Modibbo, U. U., Aliyu, B.A., Nkafamiya, I. I., The Effect of Mercerization Media on the Physical Properties of Local Plant Bast Fibres, International Journal of Physical Sciences, 4 (11), 698-704. 2009.

[22] Ubi, P. A., Abdulrahman, S. A., Effect of Sodium Hydroxide Treatment on the Mechanical Properties of Crushed and Uncrushed Luffa Cylindrical Fibre Reinforced rLDPE Composites, International Journal of Chemical, Nuclear, Materials and Metallurgical Engineering, 9, (1), 203-208. 2015.

[23] ASTM Literature References for Composite Materials $1^{\text {st }}$ edition, ASTM International West Conshohocken, Philadelphia USA, 1987.

[24] ASTM Annual Book of ASTM Standards, Section 8, vol. 08.01, ASTM International West Conshohocken, Philadelphia USA, 2005.

[25] Oladele, I. O., Omotoyinbo, J. A., Adewara, J. 0. T., Investigating the Effect of Chemical Treatment on the Constituents and Tensile Properties of Sisal Fibers, Journal of Minerals and Materials Characterization and Engineering, 9(6), 2010, 569-58. 2010. 
[26] Mwaikambo, L. Y., Ansell, M. P., 1999. The Effect of Chemical Treatment on the Properties of Hemp, Sisal, Jute, and Kapok Fibres for Composites, Angewandt Makromolekular Chemie, 272 (1), 108-116. 1999,

[27] Demirgoz, D., Elvira, C., Mano, J. F., Cunha, A. M., Piskin, E., Reis, R. L., Chemical Modification of Starch Based Biodegradable Polymeric Blends: Effects on Water uptake, Degradation Behaviour and Mechanical Properties, Polymer Degradation and Stability, 70 (2), 161-170. 2000.

[28] Hull, D., Clyne, T. W., An Introduction to Composites Materials, $2^{\text {nd }}$ edition, Cambridge Press, 1996.

[29] Aminu, S. M., Sunmonu, O., Bello, K., Effect of Chemical Modification on Mechanical Properties of Luffa Guord and Dum Palm Reinforced Composite, Standard Scientific Research and Essays, 2(10), 541-545. 2014.

[30] Sunmonu, O., Aminu, S. M. and Bello, K., Effect of alkali treatment on mechanical properties of Luffa Guord reinforced composite. Standard Scientific Research and Essays, 2(12), 2014, 841-945.

[31] El-Shekeil,Y. A., Sapuan, S. M., Algrafi, M. W., Effect of Fiber Loading on Mechanical and Morphological Properties of Cocoa Pod Husk Reinforced Thermoplastic Polyurethane Composites, Materials and Design, 64, 330333. 2014

[32] Munirah, M., Abdul, R. R., Azman, H. Characterization and Treatments of Pineapple Leaf Fiber Thermoplastic Composite for Construction Application, VOT No: 75147.

[33] Adil, D., Gope, P. C., Maheshwari, M. K., Sharma, R. K., Palm Fibre Composites Journal of Material and Environment Science,3(6), 1079-1092. 2010.

[34] Saw, S. K., Purwar, R., Nandy, S., Ghose, J., Sarkhel, G., Fabrication, Characterization and Evaluation of Luffa Cylindrical Fiber Reinforced Epoxy Composites, Bio Resources, 8 (4), , 4805-4826. 2013.
[35] Nagruib, H. M., Kandil, U. F., Hashem, A. I., Boghdadi, Y. M., Effect of Fiber Loading on the Mechanical and Physical Properties of "Green" Bagasse-Polyester Composite, Journal of Radiation Research and Applied Sciences, 8 544-548. 2015.

[36] Cao, Y., Shibata, S., Fukumoto, I., Mechanical Properties of Biodegradable Composites Reinforced with Bagasse Fibre before and after Alkali Treatments, Composites: Part A, 37(9) , 423-299. 2006.

[37] Tajeddin, B., Rahman, R. A., Abdulah, L. C., The Effect of Polyethylene Glycol on the Characteristics of Kenaf Cellulose/Low-Density Polyethylene Biocomposites, International Journal of Biological Macromolecules, 47, 292-297. 2010.

[38] Sathiskurmi, T. P., Satheeshkumar, S., Naveen, J., Glass Fiber- Reinforced Polymer Composites- A Review, Journal of Reinforced Plastics and Composites, 33(13), 12581275. 2014.

[39] Isa, M. T., Ahmed, A. S., Aderemi, B. O., Taib, R. M., Mohammed-Dabo, I. A., Effect of Fiber type and Combinations on the, Mechanical, Physical and Thermal Stability Properties of Polyester Hybrid Composites, Composites: Part B, 52, , 217-223. 2013.

[40] Suradi, S. S., Yunus, R.M., Beg, M. D. H., Rivai, M., Yusof, Z. A. M., Oil Palm Bio-Fiber Reinforced Thermoplastic Composites-Effects of Matrix Modification on Mechanical and Thermal Properties, Journal of Applied Sciences,10, 3271-3276. 2010,

[41] Bledzki, A. K., Gassan, J., Composites Reinforced with Cellulose Based Fibres, Progress in Polymer Science, 24(2), 221-74. 1999,

[42] Kabir, M. M., Wang, H., Lau, K. T., Cardona, F., Chemical Treatments on Plant-Based Natural Fibre Reinforced Polymer Composites, Composites: Part B, 43 (7), 28832892. 2012. 